\title{
Finding Home in a Canadian Public Garden
}

\author{
Amanda Leigh Hooykaas ${ }^{1}$
}

Department of Geography, Environment and Geomatics, University of Guelph, Ontario, Canada

\section{Abstract}

The experience of being "at home" is not a static entity with clear boundaries, but rather involves dynamic connections, including inside and outside and private and public. The essential characteristics or attributes of home include the act of dwelling and engaging within a space, a sense of belonging and empowerment, and a space of residence. Gardens place individuals within their own stories and bring them home: From reminding them of distant childhoods, to the selfless stewarding of public spaces, there is an intrinsic connection between people and their public gardens. Additionally, public gardens offer some re-creation of homelands-familiar sensory experiences link individuals to other times, which comfort them and ground them in this home, thereby fostering a sense of place. An investigation of the role played by volunteers in Canadian public gardens uncovers insights into the importance of place attachment, belonging, and home.

Keywords: home, public gardens, sense of place, volunteers

Recommended citation (APA 7th ed.)

Hooykaas, A. L. (2021). Finding home in a Canadian public garden. Human Ecology Review, 27(1), 65-77. doi.org/10.22459/HER.27.01.2021.04

\section{Introduction: At home in the garden}

Humans cultivate gardens; these places have been used to foster a sense of home and place in a nature we've helped to define. When we are in gardens, we develop our sense of attachment and belonging, which contribute to the development of our individual health and the collective psyches of our communities. Indeed, we require connection to place for a sense of purpose, happiness, and also for our intrinsic well-being (Hooykaas, 2009). Wilson (1984) suggests that longing for a sense of place-although few of us ever attain one-is embedded within the human psyche.

1 Corresponding author: amanda.hooykaas@uoguelph.ca. 
The desire to connect to nature is also a direct result of centuries of evolution of humans and our relationships with our natural environment; the development of a sense of place is one way for people to connect to nature and in doing so arrive at home.

In this article, volunteers of urban public gardens in Canada demonstrate how an investment of labor in such landscapes helps to foster a sense of home for those individuals, one that may also extend to the visitors of the urban public gardens.

\section{Methodology}

The topic of gardens and their interrelationship with people lends itself to an interdisciplinary methodological approach encompassing considerations of time and space as they relate to the development of a sense of place. The qualitative approach used in this exploration involved an in-depth examination of secondary literature, as well as fieldwork involving semi-structured interviews $(N=44)$, and narrative methods. Individual experiences within gardens provide much insight into the multiple aspects of place in relation to public gardens. Such experiences were explored using perceptual lenses offered by diverse writers whose work can be found in bodies of literature related to history, geography, nonfiction, and poetry (Beatley, 2005; Camus, 1970; Cresswell, 2004; Emerson, 2005; Kennedy, 1998). All these bodies of work have explored similar conceptual foundations and/or prescriptions about what impacts green spaces have upon the individual in promoting a sense of place attachment, belonging, and home. In addition, the lived stories and experiences of people who labor in gardens were sought for reasons that a narrow viewpoint might dismiss as merely idiosyncratic. From an interdisciplinary perspective, however, such investigations are crucial to understanding the value of those aspects of life that are not readily quantifiable or immediately tangible such as gardening. Through this examination, the importance of gardens to an individual's internal (psychological) and external (social) home was considered, particularly for those currently involved as volunteers at public gardens.

During research, personal interviews with volunteers of Canadian public gardens revealed that they connect those gardens with a sense of place or home. Even if volunteers do not directly name the garden they work in as a home, they often give it the same descriptors as they do their homes or, alternatively, the places in which they feel most at ease. Gardens place individuals within their own stories: From reminding them of childhoods long since passed, to the selfless act of volunteering as a contribution to make the world a more colorful place for everyone, there is an intrinsic connection between people and their public garden. Of added significance to this article is the finding that public gardens offer some re-creation of homelands, 
whether physical or emotional, for volunteers alienated from their own; and familiar sights, smells, actions, and experiences often link volunteers to other places and times, which comfort them and ground them in this "home" (Bhatti \& Church, 2001).

\section{Home as a form of place}

Home, while often considered as a physical space, is also a state of being (Aliefendioğlu \& Behçetoğulları, 2019; Kunstler, 1996; May et al., 1958; Tuan, 1990). The themes of belonging and place are also found in similar ways within the literature of gardens. This experience of being at home is not a static entity with clear boundaries but rather involves dynamic connections between inside and outside, as well as private and public (Bhatti \& Church, 2001).

The essential characteristics or attributes of home include the act of dwelling and engaging within a space, a sense of belonging and empowerment, and a space of residence - a relationship to space that may be experienced as physical, emotional, or in some other way (Aliefendioğlu \& Behçetoğulları, 2019; Fathi, 2021). The role of home as a state of being is vital to understanding our own relationships with our gardens; how we relate to our homes closely aligns with how we might relate to our gardens as places as well. The feelings experienced by people in both place and home are similar, but it is often easier for people to describe what makes them feel "at home" than "in place." One can begin to see how this central idea of place is integral to the human spirit. It is not novel. It is something that humans have been engaging with for thousands of years. The notion of place comprises more than just an element of home but for the purpose of this article, home and place are the focus, through the lens of public gardens. Public gardens offer a platform from which to view place attachment in not only a contemporary context but also through time.

\section{Finding home in a garden}

The ways humans connect to gardens have changed over time, and the definitions that apply vary tremendously even today. They include: a place in which to sustain a particular ecological function (Hansen \& DiCastri, 1992); a heterogeneous land area composed of a cluster of interacting ecosystems that is repeated in similar form throughout (Forman \& Godron, 1986); and the specific area in which one will cultivate plants (Aben \& de Wit, 1999).

In the European settlement of Canada, people were able to connect to their landscapes and neighborhoods through shared history and hope for growth and wealth. For example, the Halifax Public Gardens were established in 1867 and modeled after the Victorian gardens so familiar to the English settlers (Gardens Canada, n.d.). 
Other gardens included the Rideau Hall Gardens, a 79-acre (32-hectare) estate established in 1838 to incorporate a composition of classic English and modern garden styles, again so familiar to immigrants of that time (MacMillan et al., 2004). Importantly, in order to create any connection to the landscape, displacement has often contributed to the creation of those places (Lewicka, 2013; Rishbeth et al., 2019); Indigenous peoples were displaced and forced to search for new roots as the Europeans created and imposed their own sense of home (Lopez, 1992). The impacts of forced displacement continue to be felt in Canada today, and the role of gardens for settlers in the reclamation of home also continues.

\section{Urban public gardens in Canada}

Urban public gardens are broadly recognized today as having a much wider role than was originally conceived when first developed in North American cities. Public gardens serve to fill a niche for public engagement in the natural environment. Not everyone has the room, time, or ability to grow their own gardens within private spaces; public gardens fill this gap and offer access to those who might otherwise not have an opportunity to experience nature within a built landscape.

Public gardens, then, offer the opportunity for engagement in nature that might otherwise not be possible. Private gardens, on the other hand, are much more varied in form, purpose, and availability. Economics, culture, and experience also play a large role in the ways in which one might create and then tend to a private garden. In contrast, a public garden follows a specific mandate, is overseen by a board of directors, and is tended by many more people, of varied backgrounds. By examining public, rather than private, gardens, it is possible to see the impact that gardens, in general, have in the larger urban community.

Public gardens vary considerably in form, mandate, and size from place to place depending on the values and priorities of the key decision-makers. Landscape architects and planners, for example, may see public gardens as reflecting both historic and aesthetic character that represents both the local and the national (Beveridge, 2000). Even though gardens are perhaps viewed as having only an indirect or intangible economic contribution to the economic growth and development of an area, the public and personal resources invested in them is evidence that they are valued for their amenity and heritage, and their public goal of preserving certain values for the future. They capture a spectrum of time in a single location. The processes of growing heritage seeds, the use of time-tested tools and gardening methods, and the application of evolving approaches to garden ecology and design all illustrate many facets of both history and contemporary life found within one landscape. For example, in the Royal Botanical Gardens in Burlington, 
Ontario, one can find an arboretum, rock garden, and herbarium, plus it maintains 50 collections featuring plants of wild origin, ornamental plants, and plants of scientific and conservation importance (Royal Botanical Gardens, n.d.).

Some authors of garden literature note that the connections between place and well-being and nature and home and gardens are not explicit, yet they are often implied (Pollan, 1991; Von Baeyer \& Crawford, 1995).

Today, such green spaces remain pillars of social construction with manicured lawns and introduced and cultivated species, but they are beginning to reflect the diversity in Canadian cultures and representations of home. One example of this can be found in the Montreal Botanical Garden where one of the feature gardens is the First Nations Garden (Montreal Botanical Garden, n.d.). As was previously discussed, Indigenous people, so frequently displaced by European settlers, also have public gardens to represent their home and their roots in the landscape. These gardens often feature aspects of that connection that are culturally and historically significant to Canada. Public gardens serve to explain this connection between people and their environment, and across Canada, different gardens reflect different creations of home; examples include the Japanese and Chinese gardens in Vancouver (Japanese Nitobe Memorial Garden and Dr. Sun Yat-Sen Classical Chinese Garden), the Victorian gardens in Halifax (Halifax Public Gardens), and the First Nations garden in Montreal (Montreal Botanical Garden) (Hooykaas, 2012).

In Vancouver, the Dr. Sun Yat-Sen Garden Society (incorporated in 1981) aims to promote Chinese culture and be an integral part of the local community. The garden is not only a landscape reflecting the cultures of today, but also includes historical values:

It became clear that a physical and tangible reminder of the cultural and historical importance of Vancouver's Chinatown was needed. Therefore ... plans were made for the development of ... the first full-scale traditional Ming Dynasty classical Chinese Garden to be built outside China (Dr. Sun Yat-Sen Classical Chinese Garden, n.d., para. 5).

Gardens foster imaginations and allow them to flourish, regardless of where one is placed. For example, after World War II, Japanese Canadian ethnic identity in Southern Alberta embodied "utopian idealism intertwined with a great expectation for the end of racial discrimination and the expansion of democracy" (Fujiwara, 2010, p. 2). As self-portrayed "refugees," who had lost their homes, Japanese immigrants saw Alberta as the land where they could maintain Japanese identity, a sense of place and belonging, and loyalty to their homeland while achieving economic success, without persecution. The most concrete and monumental example of utopian expression for the immigrants was the Nikka Yuko Garden constructed in Lethbridge in 1967 to commemorate Canada's Centennial (Fujiwara, 2010). The Nikka Yuko Garden exemplifies re-creation of home and fostering of multiculturalism in a new 
landscape and is described as a symbol of international friendship. Its name was created from the Japanese words $N i$ (from Nihon meaning Japan), $k a$ from Kanada or Canada, and Yuko, which translates as "friendship" to mean "Japan-Canada friendship" (Nikka Yuko Japanese Garden, n.d.).

The Halifax Public Gardens have underpinnings of the re-creation of home for some and are considered a rare example of a formal Victorian public garden, surviving intact and relatively unspoiled in the heart of a modern city. In 1872, Richard Power was hired as the garden's first superintendent. During his tenure as superintendent, Power "oversaw the introduction of a bandstand, fountains, statues and wrought iron gates-all features of the High Victorian Pleasure Garden. They all honour a milestone in Queen Victoria's reign, a contemporary military event, or an important local personage" (Gardens Canada, n.d.). Power believed the gardens were a work of art rather than a work of nature. That sentiment endures today and, though the gardens were extensively damaged by Hurricane Juan in September 2003, major restoration and fundraising were undertaken and are ongoing to reimagine the garden as art (Friends of the Historic Public Gardens, n.d.).

The First Nations Garden of the Montreal Botanical Garden offers a different approach to public gardening, primarily that of homemaking. Opened in 2001, the garden aims to present "the close bonds Amerindians and the Inuit have always had with the plant world" (Montreal Botanical Garden, n.d., "Natives Share Their Vision" section). It is designed to evoke a natural environment, while serving as a crossroads of cultures: "A place for sharing knowledge, allowing non-Native Quebeckers to discover or rediscover the culture of the first inhabitants of North America, while offering an opportunity for the First Nations to share their traditions, wisdom and know-how" (Montreal Botanical Garden, n.d., "Discovering the Culture" section).

The First Nations Garden "avoids stereotypes; it is a contemporary garden, one inspired by First Nations and Inuit cultures" (Montreal Botanical Garden, n.d., "The Spokesman" section). In addition to highlighting Native knowledge of plants, the garden also features First Nations activities relating to plants; growing and gathering for food, medicine, and materials (Montreal Botanical Garden, n.d.). In the garden, there are clear linkages to history, combined with acknowledgment of the important role that history plays in today's Canadian society.

Gardens such as these examples help to create the colorful fabric of the urban Canadian landscape and, though notions of place and home might not be outwardly present, such cultural gardens capture the stories of other landscapes and weave them into our own. The fabric of the landscape is diverse and storied, like our own lives. Today gardens exist for not only reasons of science, social engagement, or economics but also for healing, recreation, botanics, community, and culture. Landscape architects, environmental psychologists, and urban planners have 
suggested that gardens provide a vital role in developing people's understandings of how to nurture their environments and, in turn, themselves (Minter, 1993; Von Baeyer \& Crawford, 1995; Young et al., 2020). Gardens foster well-being.

\section{The gardener as homemaker}

Public gardens reflect a variety of traditions that are maintained through volunteer associations. The dedication of these volunteers to a public pursuit that is primarily valued for its intrinsic worth raises interesting questions about the role these gardens play in sense of place and the re-creation of "home." This conception of the garden volunteer as homemaker is of value for a number of reasons. Most importantly, such an exploration can reveal much about place attachment because in public gardens volunteers contribute to a material history and legacy, a physical part of the community's built environment. There are also other benefits of such an exploration. As Lewicka (2005) and Alaimo et al. (2010) note, volunteerism advances social capital, civic engagement, and the cultural health of community: "Community gardening and beautification activities created opportunities for the development of bonding, bridging, and linking social capital" (Alaimo et al., 2010, p. 499), all of which can contribute to sense of place within a community. How these volunteers value and promote gardens in relation to feeling "at home" is important to consider and reflects the multifaceted role that urban public gardens play in urban Canadian society.

Home as "a state of being" is evident from a series of interviews conducted with volunteers who work in public gardens in Canada. The gardens examined through grounded research in this study are Maplelawn Historic Garden, Ottawa; Rockway Gardens, Kitchener; and Spadina Museum Gardens, Toronto (excerpts from interviews conducted at Maplelawn will be listed as "M-\#" in this article). Each garden was selected because of its proximity to urban populations and its active volunteer program. Although not geographically dispersed across Canada, the selected gardens are typical and representative of the wider picture of Canadian public gardens. They have different histories, were originally created for diverse purposes, and have relied on various sources of funding and support since their creation. They all have unique organizational structures. One thing that they all have in common is that they are small in size (two to seven acres [one to three hectares]), and their volunteers are active, dedicated, and part of an organized program (often called "Friends" of the garden). The experiences of volunteers in these three gardens are representative of those of volunteers in other urban public gardens across Canada with similar programs (though such programs are relatively rare). 
Within the ground-truthing portion of the research, questions were posed that elicited insight into how the Friends of the gardens experience and engage with their landscapes: natural, cultivated, and peopled. The origins of their connections to gardens were explored as well. In developing a clear picture of how the gardener experiences places, key psychological, social, and philosophical components of home are explored. Often, upon completion of the prepared questions, volunteers would offer additional insight into the topic, and this was often useful in creating a rich picture of how the individual relates to their experiences as a volunteer in an urban public garden.

If volunteers did not directly name the garden as a home, they often gave it the same descriptors as they did their homes or, alternatively, the places at which they felt most at ease: "I guess this garden can be a home for some. It has shelter, peace, and provides happiness, and I guess that's what a home should give you too" (M-10). This sentiment was shared by many of the gardeners interviewed. "My house is a roof and space and some green space that I can tend; it is comfortable and warm and welcoming. I feel connected to it. It is just right for me" (M-12). The garden where this individual volunteers their time was described in similar terms: "It's a special place, with just the right flowers and plants-heritage ones. The wall makes it comfortable. The gardens make it pretty. And I feel happy here" (M-12). Most volunteers viewed "their" garden as a sanctuary from the urban environment in which it existed.

In one of his earliest essays, titled "Love of Life," philosopher Albert Camus describes his own experience of wellness as a fusion of mind and garden. While walking into a cloister garden in San Francisco, he "melt[s] into this smell of silence, becoming nothing more than ... the flight of birds whose shadows I could see on the still sunlit portions of the wall" (Camus, 1970, p. 55). For a moment-and Camus's affirmation of life is all about moments of intensity rather than the continuum of experience- the fusion between state of mind and garden is so complete that the former upholds and keeps in being the latter:

In the sharp sound of wingbeats as the pigeons flew away, the sudden, snug silence in the middle of the garden, in the lonely squeaking of the chain on its well, I found a new and yet familiar flavor. I was lucid and smiling before this unique play of experiences. A single gesture, I felt, would be enough to shatter this crystal in which the world's face was smiling. Something would come undone-the flight of pigeons would die and each would slowly tumble on its outstretched wings. Only my silence and immobility lent plausibility to what looked like an illusion. (Camus, 1970, p. 55)

One gardener suggested that "no matter how terrible the world is, when you leave a garden, you can't help but be happy" (M-5). 
Because the concepts of home and place are difficult to separate, findings from interviews do not distinguish between the two concepts. It is important to recognize that often when people talk about home, they are talking about sense of place; for some, the word "home" reminds them of place and for others it reminds them of childhood. Through the interviews, the language of home became one of familiarity, tranquility, stability, beauty, and comfort. Few volunteers directly linked home with the garden, but when describing the garden, used the same descriptors, which suggests that the experiences of gardens may make them feel at home as well, which also links them to their childhood and other aspects of sense of place.

The connection between home and sense of place endures with the Friends. Each garden reflects some aspect of Canadian culture: whether it is that of the British influence at Maplelawn, the German immigrants at Rockway, or the wealthy family at Spadina, descendants of long-settled early colonists. This theme of homemaking through gardening in Canada is not new but has been written about since the days of Catharine Parr Traill and her contemporaries. This effort to settle is about many things, but within the garden it is in part about coming home. The following paragraph fully captures this sentiment and, as such, is presented here in its entirety:

Settling is about transformation and violence, it is about tenderness and cruelty, hope and despair. Settling invokes memories of old homes founded in new places as well as of new landscapes settling into old hearts. Settling is also as much about seeing and feeling as it is about transformation and movement, of seeing one's future in a new country ten years hence, of feeling the soil yielding slightly under one's feet after wet weather, of arching up one's neck to view a magically unfamiliar nightscape. (Beattie \& Holmes, 2011, p. 75)

When examining the experience of place in the garden today, two aspects of the garden are often suggested as being present: the sense of calm and the sense of wellness. It is through such experience that the very culture of volunteerism is established within the gardens. This volunteerism is not simply an offering of skills for today (Heidegger, 1962), but the Friends of the gardens actually become the stewards of the landscape both today and into the future, dwelling as a member of the place.

\section{Bringing it all home: The connection between sense of place and public gardens}

Applying the concept of home to sense of place in urban spaces reveals an opportunity for reinhabitation-coming home-through gardens, which offer opportunities to reconnect with a landscape often chaotic and troublesome. David Orr (1992) agrees with this concept: "The study of place ... has significance in reeducating people in the art of living well where they are" (p. 130). Orr suggests, 
"a resident is a temporary occupant, putting down few roots and investing little, knowing little and perhaps caring little for the immediate locale beyond its ability to gratify" (p. 130). Conversely, inhabitants-people truly at home in a placeexhibit "an intimate, organic, and mutually nurturing relationship with a place. Good inhabitance is an art requiring detailed knowledge of a place, the capacity for observation, and a sense of care and rootedness" (Orr, 1992, p. 130). For a country that is so multicultural, reinhabitation is important and allows a connection with the landscape that may lead to stewardship of that place.

Not all people feel the pull to home in a garden, however. This lack of connection in the garden for some individuals — particularly generations younger than the retirees who make up the majority of the Friends of the gardens - is something to note as a possible avenue through which to reengage the larger community in the garden to ensure its longevity. The gardener is the epitome of the reinhabitant, demonstrating commitment to place through time and space, with recognition of beauty, history, and personal attachment of thick places. As Heidegger suggested in his discussion of dwelling, this relationship between place and person permits space for wellbeing, and many scholars agree (Albrecht, 2005; Gruenewald, 2003; Orr, 1992). This reinhabitation was not something discussed during interviews but is certainly an important aspect of sense-making in the garden, particularly for people who volunteer within such landscapes.

For the multicultural landscape, the fabric of public gardens must be equally colorful. The development of cultural gardens such as the gardens representing Japan, China, and the First Nations is allowing for the re-creation of home (Keane \& Ohashi, 1996; Keswick, 2003; Montreal Botanical Garden, n.d.). In coming home through such landscapes, people are coming into gardens.

The gardens are created by people but so too are people created by the gardens. Identity, community, home, and place all relate when some people consider their own experiences in public gardens. Initially created for purposes other than this, public gardens today occupy many additional niches within our lives: sanctuary and solace, comfort and familiarity. They tell us of our combined and individual heritages, our stories of who we are and how we connect to this world. Gardens bring us home.

\section{References}

Aben, R., \& de Wit, S. (1999). The enclosed garden: History and development of the hortus conclusus and its reintroduction into the present-day urban landscape. 010 Publishers. 
Alaimo, K., Reischl, T. M., \& Allen, J. O. (2010). Community gardening, neighborhood meetings, and social capital. Journal of Community Psychology, 38(4), 497-514. doi.org/ $10.1002 /$ jcop. 20378

Albrecht, G. (2005). 'Solastalgia': A new concept in health and identity. Philosophy, Activism, Nature, 3, 41-55. doi.org/10.4225/03/584f410704696

Aliefendioğlu, H., \& Behçetoğulları, P. (2019). Displacement, memory and home(less) identities: Turkish Cypriot women's narratives. Gender, Place and Culture, 26(10), 1472 1492. doi.org/10.1080/0966369X.2018.1556613

Beatley, T. (2005). Native to nowhere: Sustaining home and community in a global age. Island Press.

Beattie, J. J., \& Holmes, K. (2011). Reflections on the history of Australasian gardens and landscapes. Studies in the History of Gardens \& Landscapes, 31(2), 75-82. doi.org/ $10.1080 / 14601176.2011 .556366$

Beveridge, C. E. (2000). Olmsted-his essential theory. National Association for Olmsted Parks. www.olmsted.org/the-olmsted-legacy/olmsted-theory-and-design-principles/ olmsted-his-essential-theory (Reprinted from "Olmsted-his essential theory," 2000, Twenty-fifth anniversary issue of Nineteenth Century, the Journal of the Victorian Society in America, 20(2), 32-37).

Bhatti, M., \& Church, A. (2001). Cultivating natures: Homes and gardens in late modernity. Sociology, 35(2), 365-383. doi.org/10.1177/S0038038501000177

Camus, A. (1970). Lyrical and critical essays (P. Thody, Ed.; E. C. Kennedy, Trans.). Vintage.

Cresswell, T. (2004). Place: A short introduction. Blackwell Publishing.

Dr. Sun Yat-Sen Classical Chinese Garden. (n.d.). Why was the garden created? vancouverchinesegarden.com/our-story/

Emerson, R. W. (2005). Essays and poems (P. Norberg, Ed.). Barnes \& Noble. (Original work published 1856).

Fathi, M. (2021). "My life is on hold": Examining home, belonging and temporality among migrant men in Ireland. Gender, Place and Culture. Advance online publication. doi.org/ 10.1080/0966369X.2021.1916445

Forman, R. T. T., \& Godron, M. (1986). Landscape ecology. John Wiley and Sons.

Friends of the Historic Public Gardens. (n.d.). History of the gardens. www.halifaxpublic gardens.ca/history-of-the-gardens

Fujiwara, A. (2010). Imagining postwar utopia: Japanese Canadians in Southern Alberta and the Nikka Yuko Japanese Garden. Alberta History, 58(2), 2-9. link.gale.com/apps/ doc/A233501471/AONE?u=anon $\sim 9 \mathrm{e} 2 \mathrm{cfd} 65 \&$ sid=googleScholar\&xid=df0461e7 
Gardens Canada. (n.d.). Halifax Public Gardens: Halifax, Nova Scotia. gardenscanada.ca/ places/halifax-public-gardens/

Gruenewald, D. A. (2003). Best of both worlds: A critical pedagogy of place. Educational Researcher, 32(4), 3-12. doi.org/10.3102/0013189X032004003

Hansen, A. J., \& DiCastri, F. (Eds). (1992). Landscape boundaries: Consequences for biotic diversity and ecological flows. Springer-Verlag.

Heidegger, M. (1962). Being and time (J. Macquarrie \& E. Robinson, Trans.). Harper \& Row. (Original work published 1927).

Hooykaas, A. L. (2009). The study of placelessness: Toward a conceptual framework. The International Journal of Environmental, Cultural, Economic and Social Sustainability, 5(3), 295-304. doi.org/10.18848/1832-2077/CGP/v05i03/54591

Hooykaas, A. L. (2012). Enduring gardens: Woven by friends into the fabric of the urban community [Doctoral dissertation, University of Waterloo]. hdl.handle.net/10012/7154

Keane, M. P., \& Ohashi, H. (1996). Japanese garden design. Charles E. Tuttle Publishing.

Kennedy, D. (1998). An ecology of enchantment: A year in the life of a garden. Greystone Books.

Keswick, M. (2003). The Chinese garden (2nd ed.). Frances Lincoln.

Kunstler, J. H. (1996). Home from nowhere: Remaking our everyday world for the 21st century. Simon \& Schuster.

Lewicka, M. (2005). Ways to make people active: The role of place attachment, cultural capital, and neighborhood ties. Journal of Environmental Psychology, 25(4), 381-395. doi.org/10.1016/j.jenvp.2005.10.004

Lewicka, M. (2013). Localism and Activity as two dimensions of people-place bonding: The role of cultural capital. Journal of Environmental Psychology, 36, 43-53. doi.org/ 10.1016/j.jenvp.2013.07.002

Lopez, B. (1992). The rediscovery of North America. Vintage Books.

MacMillan, M. O., Harris, M., \& Desjardins, A. (2004). Canada's house: Rideau Hall and the invention of a Canadian home. Knopf Canada.

May, R., Angel, E., \& Ellenberger, H., F. (1958). Existence: A new dimension in psychiatry and psychology. Jason Aronson Inc.

Minter, S. (1993). The healing garden: A natural haven for emotional and physical well-being. Headline Book Publishing.

Montreal Botanical Garden. (n.d.). First Nations Garden. espacepourlavie.ca/en/firstnations-garden

Nikka Yuko Japanese Garden. (n.d.). About the garden: History. nikkayuko.com/detail.asp? $\mathrm{ID}=85 \& \mathrm{Cat} \mathrm{ID}=1$ 
Orr, D. W. (1992). Ecological literacy: Education and the transition to a postmodern world. State University of New York Press.

Pollan, M. (1991). Second nature: A gardener's education. Dell Publishing.

Rishbeth, C., Blachnicka-Ciacek, D., \& Darling, J. (2019). Participation and wellbeing in urban greenspace: "Curating sociability" for refugees and asylum seekers. Geoforum, 106, 125-134. doi.org/10.1016/j.geoforum.2019.07.014

Royal Botanical Gardens. (n.d.). Horticulture \& collections. www.rbg.ca/plants-conservation/ horticulture-collections/

Tuan, Y. F. (1990). Topophilia: A study of environmental perception, attitudes, and values (2nd ed.). Columbia University Press.

Von Baeyer, E., \& Crawford, P. (Eds). (1995). Garden voices: Two centuries of Canadian garden writing. Random House Canada.

Wilson, E. O. (1984). Biophilia: The human bond with other species. Harvard University Press.

Young, C., Hofmann, M., Frey, D., Moretti, M., \& Bauer, N. (2020). Psychological restoration in urban gardens related to garden type, biodiversity and garden-related stress. Landscape and Urban Planning, 198, Article 103777. doi.org/10.1016/j.landurbplan.2020.103777 
This text is taken from Human Ecology Review, Volume 27, Number 1, 2021, published by ANU Press, The Australian National University, Canberra, Australia.

doi.org/10.22459/HER.27.01.2021.04 